\title{
Steam Power Plant Design Upgrading (Case Study: Khoms Steam Power Plant)
}

\author{
Hesham G. Ibrahim (Corresponding author) \\ Chemical Engineering Department, Faculty of Engineering, Al-Mergheb University \\ P.O. box 41161, Al-Khoms City, Libya \\ Tel: 218-92-582-6491Ｅ-mail: hesham.ibrahim80@gmail.com
}

Mokhtar S. Elatrash

Environmental Science Department, Faculty of Science

Al-Mergheb University, Al-Khoms City, Libya

Tel: 218-92-255-5664 E-mail: dr_m_elatrash@hotmail.com

Aly Y. Okasha

Environmental Science Department, Faculty of Science

Al-Mergheb University, Al-Khoms City, Libya

Tel: 218-92-541-1637_E-mail: aly_okasha2002@yahoo.com

\begin{abstract}
Received: December 1, $2011 \quad$ Accepted: December 13, $2011 \quad$ Published: December 31, 2011
doi:10.5539/eer.v1n1p202 URL: http://dx.doi.org/10.5539/eer.v1n1p202
\end{abstract}

\begin{abstract}
Built during the seventies and commissioned in 1980, Khoms Steam Power Plant consists of four units. A proposed design modifications based on Hysys simulation is to improve the overall efficiency, reduce gas emissions and lower operation and maintenance costs.

Five proposed modifications based on reduction of heat loss from the condenser and lowering heating rate reveal that a single open feedwater heater process is the optimum design modification of Rankine cycle to achieve the targeted objectives.
\end{abstract}

Keywords: Steam turbine, Condenser, Efficiency, Rankine cycle, Hysys

\section{Introduction}

A steam power plant cycle is the group of interconnected main equipment components selected for optimum thermodynamic characteristics to achieve optimum performance to generate electrical power. Selection of the optimum cycle depends upon plant size, cost, construction, operation and maintenance.

Electrical power generation through steam power plants in Libya constituted nearly $25.4 \%$ of the total national power production during 2008 (GECOL, 2008). This study presents a simulation by HYSYS to examine the possibility of upgrading the efficiency and the reliability of the Rankine cycle at Khoms steam power plant. Proposed upgraded designs aim to enhance the overall efficiency, reduce cost of maintenance, fuel consumption and heat losses. Upgrading Hysys has proven to be an efficient simulation tool in upgrading and verifying the performance industrial process such as simulation of a gas power plant by Robles (2002) and $\mathrm{CO}_{2}$ Removal by Amine Absorption from a Gas Based Power Plant by Øi, (2007).

\section{Rankine Cycle}

\subsection{Description of cycle}

The most prominent physical features of a modern steam power plant (other than its smokestack) are the steam generator and the boiler. Combustion of a fossil fuel such as oil or natural gas produces hot combustion gases that transfer heat to water passing through tubes in the steam generator. The heat transfer to the incoming water 
(feed water) primarily raises water temperature to become a saturated liquid that evaporates it form a saturated vapor, and ultimately raises its temperature further to create a superheated steam.

Saturated or superheated steam in steam power plant Figure 1a enters the turbine at state 1, where it expands isotropically to the exit pressure at state 2 . The steam is then condensed at constant pressure and temperature to a saturated liquid, state 3 . Heat removal from steam in the condenser is typically transferred to the cooling water. The saturated liquid then flows through the pump which increases its pressure to the boiler pressure (state 4), where the water is first heated to the saturation temperature, boiled and typically superheated to state 1 . Then the whole cycle is repeated in which the working fluid undergoes a cyclic process as illustrated in Figure $1 \mathrm{~b}$.

In order to return the steam to the high-pressure of the steam generator to continue the cycle, the low- pressure steam leaving the turbine at state 2 is first condensed to a liquid at state 3 and then pressurized in a pump to state 4. The high pressure liquid water is then ready for its next pass through the steam generator to state 1 and around the Rankine cycle again. The steam generator and condenser both may be thought of as types of heat exchangers.

At the start of the twentieth century reciprocating steam engines extracted thermal energy from steam and converted linear reciprocating motion to rotary motion, to provide shaft power for industry. Today, highly efficient steam turbines convert thermal energy of steam directly to rotary motion. Eliminating the intermediate step of conversion of thermal energy into the linear motion of a piston was an important factor in the success of the steam turbine in electric power generation. The resulting high rotational speed, reliability, and power output of the turbine and the development of electrical distribution systems allowed the centralization of power production in a few large plants capable of serving many industrial and residential customers over a wide geographic area.

The final link in the conversion of chemical energy to thermal energy to mechanical energy to electricity is the electrical generator. The rotating shaft of the electrical generator usually is directly coupled to the turbine drive shaft.

Since at present there is no economical way to store the large quantities of electricity produced by a power plant, the generating system must adapt, from moment to moment, to the varying demands for electricity from its customers. It is therefore important that a power company have both sufficient generation capacity to reliably satisfy the maximum demand and generation equipment capable of adapting to varying load.

\subsection{Conventional steam power plants}

In a real Rankine cycle such as that used in steam power plants as shown in Figure 2, the compression by the pump and the expansion in the turbine are not isentropic. In other words, these processes are non-reversible and entropy is increased during the two processes. This somewhat increases the power required by the pump and decreases the power generated by the turbine.

A measure of the effectiveness of an energy conversion device is its thermal efficiency which is defined as the ratio of the Heat equivalent of mechanical energy transmitted to turbine shaft to the heat supplied from external sources. Also, overall efficiency defined as the ratio of the cycle net work to the heat supplied from external sources. Both are given below (Arjun, 2008);

$$
\eta_{\text {Thermal }}=\left|\frac{W_{T}}{Q_{H}}\right| * 100 \%
$$

$W_{T}$ : Heat equivalent to power output from turbine, $(\mathrm{kW})$

$Q_{H}$ : Heat into the cycle by combustion of fuel, $(\mathrm{kW})$.

The thermal efficiency of a steam power station is about $30 \% \pm 2$. Also, the overall efficiency of steam power station is (Jones and Dugan, 1995; Arjun, 2008);

$$
\eta_{\text {Overall }}=\left|\frac{W_{T}-W_{P}}{Q_{H}}\right| * 100 \%
$$

$W_{T}$ : Heat equivalent to power output from turbine, $(\mathrm{kW})$

$W_{P}$ : Heat equivalent to power input to pump, $(\mathrm{kW})$

$Q_{H}$ : Heat into the cycle by combustion of fuel, $(\mathrm{kW})$. 
The overall efficiency of steam power station is about $29 \%$. It is seen that overall efficiency is less than thermal efficiency. A loss of about $1 \%$ occurs in the alternator.

Another measure of efficiency commonly employed by power plant engineers is the heat rate, that is, the ratio of the rate of heat addition in conventional heat units to the net power output in conventional power units. Because the rate of heat addition is proportional to the fuel consumption rate, the heat rate is a measure of fuel utilization rate per unit of power output (Singer, 1981).

\subsection{Problems associated with steam power plant}

Steam turbine efficiency is limited by water droplets formation. As steam leaves the turbine, it is typically wet. As water condenses, water droplets hit the turbine blades at high speed causing pitting and erosion, which gradually reduces the life expectancy of the blades and lowers its efficiency as shown in Figure 3.

The low overall efficiency of a steam power station of nearly $29 \%$ is attributed to a large amount of wasted heat in the condenser and other parts of plant. The heat loss in the condenser is unavoidable as heat energy cannot be converted into mechanical energy without temperature difference. The greater the temperature difference the greater is the heat energy converted into mechanical energy. This necessitates keeping the temperature of the condenser at minimal.

\section{Modified Processes of Conventional Rankine Cycle}

\subsection{Reheating cycles}

A common modification of the Rankine cycle in large power plants involves interrupting the steam expansion in the turbine to add more heat to the steam before completing the turbine expansion. Reheating process of extracted steam from a high-pressure (HP) turbine through the "cold reheat" line Figure 4a restores steam to a temperature comparable to the throttle temperature of the high pressure turbine. The reenergized steam is routed through the "hot reheat" line to the low-pressure turbine for completion of the expansion to the condenser pressure.

Furthermore, reheating tends to increase the average temperature at which heat is added. If the low-pressure turbine exhaust state is superheated, the use of reheat may also increase the average temperature at which heat is rejected. The thermal efficiency may therefore increase or decrease, depending on specific cycle conditions. Thus, reheating process yields an increase in net work, a dryer turbine exhaust, and possible improved cycle efficiency.

Note that the net work of the reheat cycle is the algebraic sum of the work of the two turbines and the pump work. In addition, that the total added heat is the sum of the heat added in the feedwater and reheat passes through the steam generator. Thus the overall efficiency of the reheat cycle is (Kapooria, et al., 2008):

$$
\eta_{\text {Overall }}=\left|\frac{W_{T 1}+W_{T 2}-W_{P}}{Q_{H 1}+Q_{H 2}}\right| * 100 \%
$$

Figure $4 \mathrm{~b}$ shows that reheat shifts the turbine expansion process away from the two-phase region towards the superheat region of the $T-S$ diagram, thus drying the turbine exhaust.

\subsection{Regeneration and feedwater heaters}

Rankine cycle efficiency may be improved by increasing the average water temperature at which heat is received. This could be accomplished by an internal transfer of heat from higher-temperature steam to low-temperature feedwater. An internal transfer of heat that reduces or eliminates low-temperature additions of external heat to the working fluid is known as regeneration.

\subsubsection{Open feedwater heaters}

Regeneration is accomplished in all large-scale, modern power plants through the use of feedwater heaters. In open feedwater heaters, a small amount of steam mixes directly with the feedwater to raise its temperature. A feedwater heater $(\mathrm{FWH})$ is a heat exchanger in which the latent heat (and sometimes superheat) of small amounts of steam is used to increase the temperature of liquid phase (feedwater) flowing to the steam generator providing the internal transfer of heat. Steam drawn from a turbine for feedwater heating or other purposes is called extraction steam as shown in Figure 5a.

The function of feedwater heaters is to use the energy of extraction steam to reduce the addition of low-temperature external heat by raising the temperature of the feedwater before it arrives at the steam generator. Feedwater heaters are therefore insulated to avoid heat loss to the surrounding. Since the heat loss is negligible 
compared with the energy through flow, feedwater heaters are usually treated as adiabatic devices. Therefore, the overall cycle efficiency Figure $5 \mathrm{~b}$ is calculated as follows;

$$
\eta_{\text {Overall }}=\left|\frac{W_{T 1}+W_{T 2}-W_{P 1}-W_{P 2}}{Q_{H}}\right| * 100 \%
$$

\subsubsection{Closed feedwater heaters}

Feedwater heating in open feedwater heaters occurs by mixing of extraction steam and feedwater. Feedwater heating can also be accomplished in shell/tube-type heat exchangers, where extraction steam does not mix with the feedwater. In closed feedwater heaters, feedwater passes through banks of tubes whereas steam condenses on the external tube surfaces in these heaters. Feedwater heaters normally are employed in two configurations in power plants:

- $\quad$ Throttled Condensate, as shown in Figure 6.

- $\quad$ Pumped Condensate, as shown in Figure 7.

\subsection{Reheating and closed feedwater heaters cycle}

As the LP-turbine exhaust quality for open and closed heater cycles are similar to the simple Rankine cycle are unacceptable, a combination of reheating and regeneration through feedwater heating may be more desirable as illustrated in Figure 8.

\section{Simulation of Steam Power Plant Cycle Processes}

A steady-state simulation of steam power plant cycles using HYSYS is applied to all the cycles described previously.

\subsection{HYSYS application}

All the necessary information pertaining to pure component flash and physical property calculations are contained within the Fluid Package. This advantage allows defining all the required information inside a single entity. In this application, the selected thermodynamic model is SRK. During the simulation by HYSYS under steady state mode, a choice of a fluid package can be problematic as most fluids result in liquid formation at the exit of the turbine and hence the thermodynamic package must be discarded. The working fluid in this case is water.

\subsection{Case study}

The main input data to the simulated process represent the operational conditions of Khoms Steam Power Plant in western Libya. The real data is presented in Table 1 where the other data are generated by HYSYS using this data.

\section{Results and Discussion}

The credibility of Hysys is established through configuration No.1 (Real Rankine Cycle), such that the actual overall efficiency is $3224 \%$ (NSPP, 2010), where the Hysys simulation based on the actual data yield $32.16 \%$ overall efficiency. Therefore, the current Hysys simulation can be regarded as an efficient approved for cycle modifications and configuration No. 1 serves as a reference for the other configurations.

Detailed results obtained from each cycle are shown in Figures 9-12 respectively. Table 2 presents results and sets a comparison between the calculated results for the plant configurations into consideration.

The results reveal that configuration No. 2 offers highest value of net outlet power water droplet free exit stream from turbine in comparison with the other configurations, however, this configuration output is dependent on large fuel consumption and associated with high energy losses at condenser as shown in Figures $9 \& 10$. Reheating limits or eliminates moisture at the turbine exit reducing maintenance cost and improves efficiency. Presence of moisture by nearly $10 \%$ or higher in the turbine exhaust can cause erosion of blades near the turbine exit and reduce energy conversion efficiency (Smith et al., 1996 and; NSPP, 2010). In contrast, configuration No. 3 offers the highest efficiency (Figure 11) at the lowest amount of fuel and the smallest turbine exit stream quality and net power.

Configuration No. 6 is a middle case between configurations No. $2 \& 3$, it is characterized by a higher net power output compared with the conventional configuration, small amount of heat losses by condenser and a low value of heating rate compared with the other water droplets free turbine exit steam configurations.

Despite the insignificant differences between the modified cycle efficiencies and the original cycle efficiency 
may seem, the difference in fuel consumption can be of a great economic importance. These differences are reported by Shibani and Najah (2006) and illustrated in Figure 10 where the price of heavy fuel oil, HFO, in local market is bout $207 \$ /$ Ton. Figure 12 reveals that the choices of cycle and design characteristics are of a great significance.

Therefore, configurations No.3 and No.4 can be considered as better alternative designs than the original for their lowest consumption of fuels and high overall efficiencies. However, configuration No. 3 is more economic compared to No. 4 as the heating rate of configuration No.3 is lesser than that of configuration No.4 as illustrated in Figure 12.

\section{Conclusion}

Examination of a number alternative designs to upgrade the existing Khoms Steam Plant done in order to improve thermal and overall efficiencies is achieved by HYSYS. The efficiency of Rankine cycle is improved by using an intermediate reheat cycle in a number of configurations. A low overall efficiency of a conventional Rankin steam power plant of nearly $32.16 \%$ is mainly attributed to a large amount of wasted heat in condensers and in other parts of the plant. The results indicate that configuration No.3 offers the highest efficiency and lesser amount of energy consumption than other the configurations. Therefore, modification of the original design based on configuration No. 3 can improve the efficiency from $32.16 \%$ to $35 \%$ resulting in reduced operation and maintenance costs. The proposed modification has a positive impact on the environment as it reduces gas emissions as a result of decreasing the heating rate.

\section{References}

Arjun M. (2008). Efficiency of Steam Power Plant. [Online] Available: http://electricalandelectronics.org /2008/09/20/efficiency-of-steam-power-station/

GECOL (General Electricity Company of Libya). (2008). GECOL database for 2008. [Online] Available: www.Gecol.ly

Ibrahim H. G., Okasha A. Y. \& Elkhalidy A. G. (2010). Improve Performance and Efficiency of the Steam Power Plant". $1^{\text {st }}$ Conference on Petroleum Resources and Manufacturing, (October 27-28, 2010), Brega, Libya.

Jones, J. B. \& Dugan, R. E. (1995). Engineering Thermodynamics. (1 ${ }^{\text {st }}$ ed.). Prentice Hall, USA.

Kapooria, R. K., Kumar, S. \& Kasana, K. (2008). An Analysis of a thermal power plant working on a Rankine cycle: A theoretical investigation. J. of Energy in Southern Africa, 19(1), 77-83. [Online] Available: www.erc.uct.ac.za/jesa/volume19/19-1jesa-kapooria-etal.pdfSimilar

NSPP (National Steam Power Plant). (2010). data sheets.

Øi, L. R. (2007). Aspen HYSYS Simulation of $\mathrm{CO}_{2}$ Removal by Amine Absorption from a Gas Based Power Plant, SIMS2007 Conference, Gøteborg, October 30-31 ${ }^{\text {st }}$ [Online] Available: www.ep.liu.se/ecp/027/008/ecp072708.pdf

Robles, J. M. (2002). Simulation of a gas power plant. [Online] Available: www.nt.ntnu.no/users/skoge/diplom/.../Robles.../gaspowerplant.pdf

Shibani, M. \& Najah, N. (2006). Studying the effect of fuel type and cost on the economics of power generation. 3rd Technologies of Oil and Gas Congress (TOG 3), Tripoli/Libya.

Singer, J. G. (Ed.). (1981). Combustion/Fossil Power Systems. Windsor, Conn.: Combustion Engineering Company.

Smith, J. M., Van Nesss, H. C. \& Abbott, M. M. (1996). Introduction to Chemical Engineering Thermodynamics. (5th ed.), McGraw-Hill, Singapore. 
Table 1. Operating conditions data of Khoms Steam Power plant, (GECOL, 2008; NSPP, 2010)

\begin{tabular}{|l|l|l|}
\hline Data & Units & Value \\
\hline No. of units & -- & 4 \\
\hline Design Load & $M W$ & 125 \\
\hline Operating load & $M W$ & 100 \\
\hline Fuel Type & -- & H.F.O. \\
\hline Steam flow rate & $T / h r$ & 375 \\
\hline Steam Exit temperature from turbine & ${ }^{\circ} \mathrm{C}$ & 540 \\
\hline Steam Exit pressure from C.C. & $B a r$ & 128 \\
\hline Temperature of C.C. & ${ }^{\circ} \mathrm{C}$ & 1000 \\
\hline Fuel flow rate for C.C. & $T / h r$ & 25.34 \\
\hline Heat of combustion of Fuel & $\mathrm{Kcal} / \mathrm{kg}$ & 10636 \\
\hline
\end{tabular}

Note: this operating condition of the plant used as input data to a Hysys program to simulation the real process site.

Table 2. Comparison of suggested configurations of Khoms steam power plant cycle

\begin{tabular}{|l|l|l|l|l|l|l|}
\hline \multirow{2}{*}{$\begin{array}{l}\text { Data } \\
\text { Configuration }\end{array}$} & $\begin{array}{l}\text { Net Power } \\
\text { out }\end{array}$ & $\begin{array}{l}\text { Overall } \\
\text { Efficiency }\end{array}$ & $\begin{array}{l}\text { Thermal } \\
\text { Efficiency }\end{array}$ & $\begin{array}{l}\text { Heating } \\
\text { Rate }\end{array}$ & $\begin{array}{l}\text { Turbine Exit } \\
\text { Quality }\end{array}$ & Q condenser losses \\
\cline { 2 - 7 } & $\boldsymbol{M} \boldsymbol{\%}$ & $\boldsymbol{\%}$ & $\boldsymbol{B t u} / \boldsymbol{h r} . \boldsymbol{K} \boldsymbol{W}$ & $\boldsymbol{V}$ ap. $\boldsymbol{F}$. & $\boldsymbol{M} \boldsymbol{W}$ \\
\hline No. 1 & 100.8288 & 32.16158 & 32.754883 & 10148.043 & 0.897 & 213 \\
\hline No. 2 & 129.0672 & 33.11488 & 33.589275 & 10148.043 & 1 & 260.7234 \\
\hline No.3 & 95.87698 & 34.79238 & 35.511641 & 9563.6988 & 0.891846 & 179.692 \\
\hline No. 4 & 95.78875 & 34.77512 & 35.450998 & 9580.0587 & 0.891846 & 179.6632 \\
\hline No. 5 & 97.37174 & 34.67888 & 35.341551 & 9609.7267 & 0.891846 & 184.9913 \\
\hline No. 6 & 106.2098 & 33.73156 & 34.322492 & 9895.0462 & 1 & 208.6579 \\
\hline
\end{tabular}

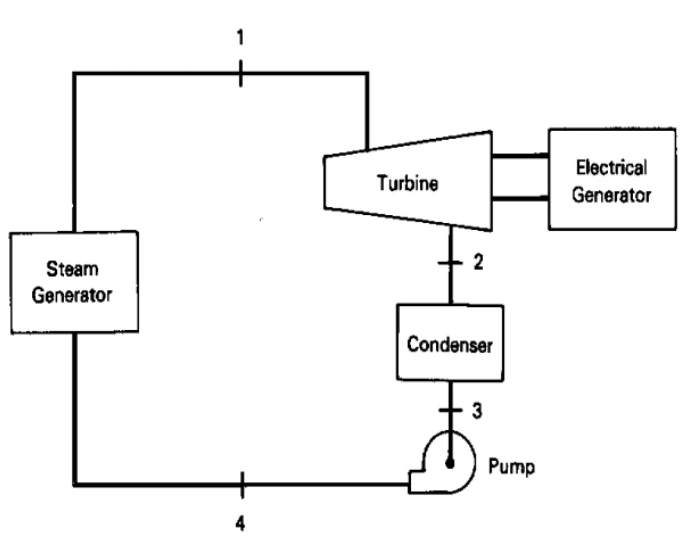

a) Flow Cycle

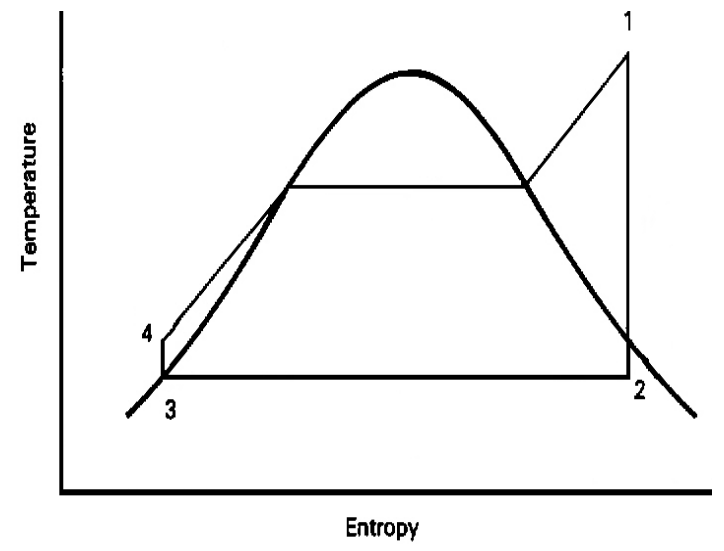

b) T-S diagram

Figure 1. Ideal Rankine cycle 


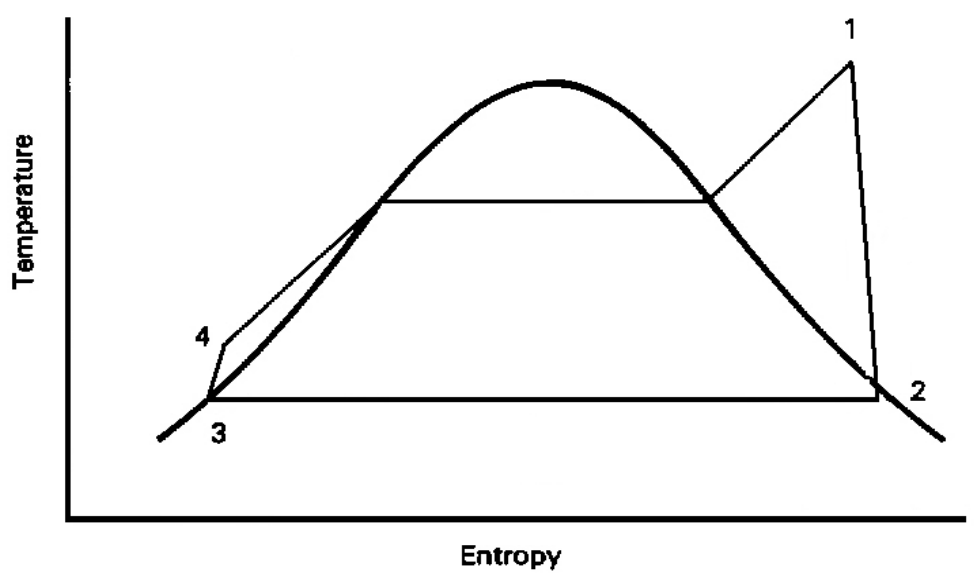

Figure 2. Real Steam Power Plant
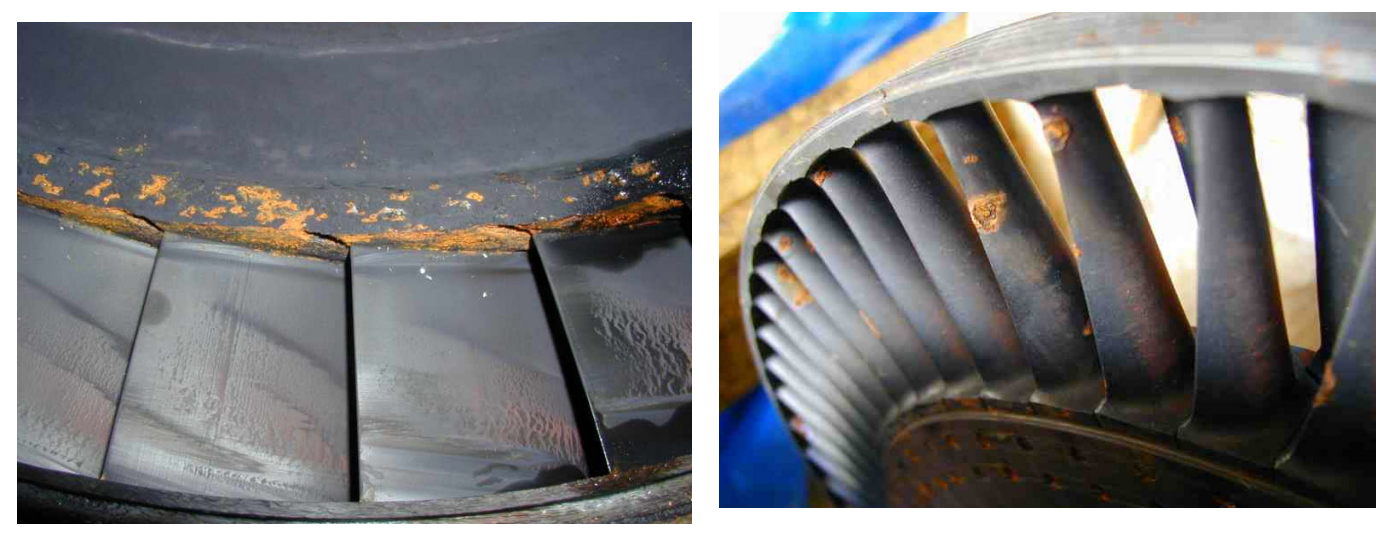

Figure 3. Erosion and pitting of steam turbine blades [Ibrahim et al., 2010]

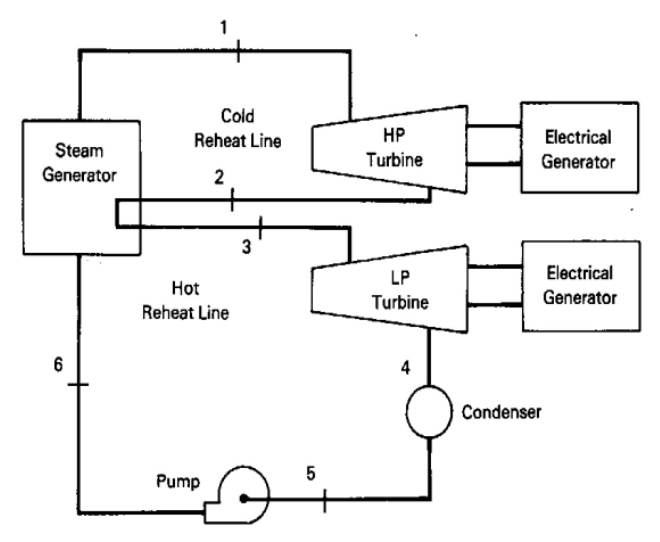

a) Flow Cycle

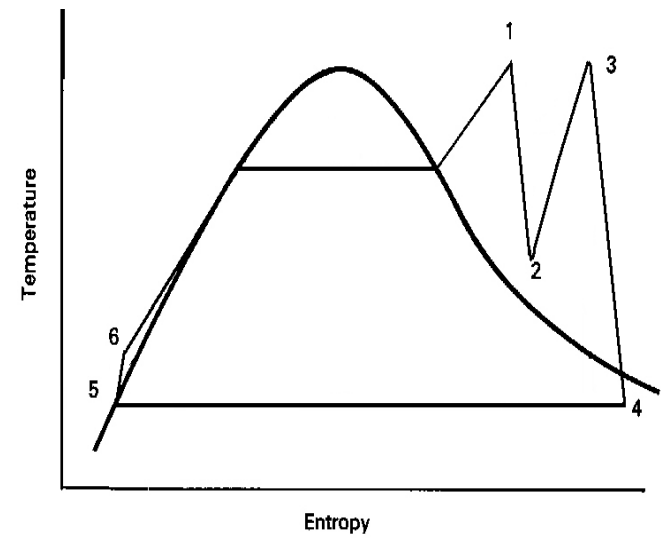

b) T-S diagram

Figure 4. Reheat Cycle of Rankine Process 


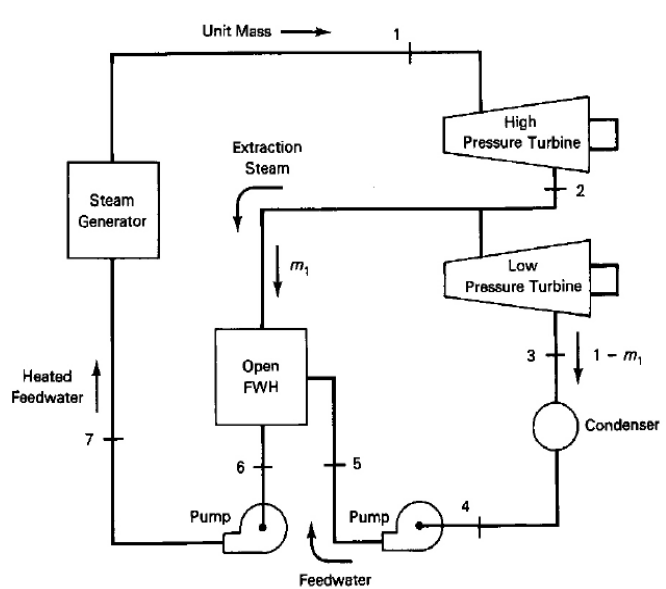

a) Flow Cycle

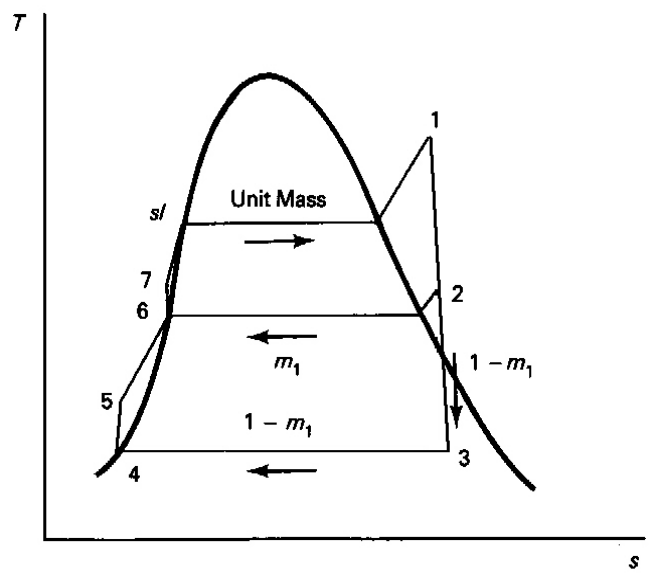

b) T-S diagram

Figure 5. Regenerative Rankine cycle with a single open feedwater heater process

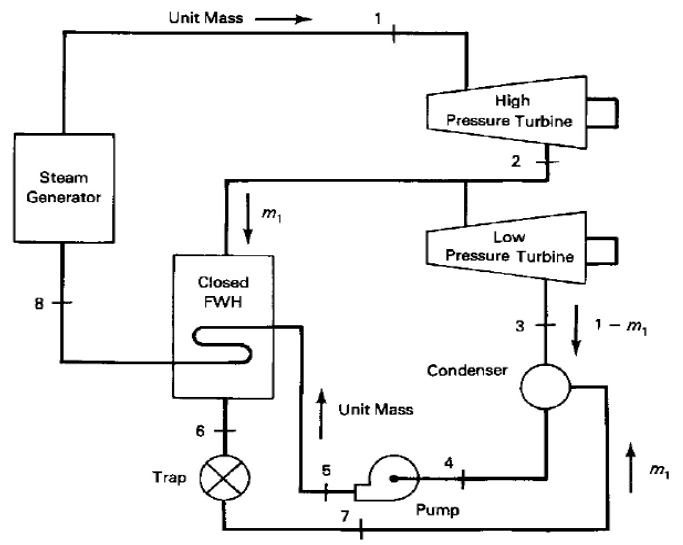

a) Flow Cycle

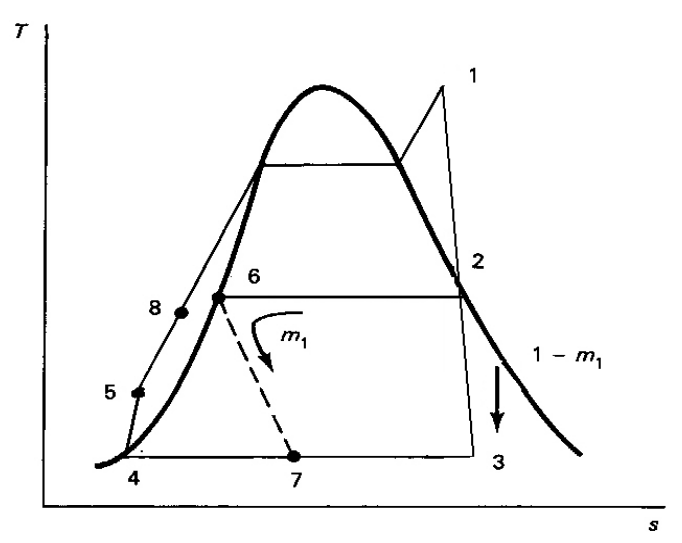

b) T-S diagram

Figure 6. Regenerative Rankine cycle with closed feedwater heater and throttled condensate

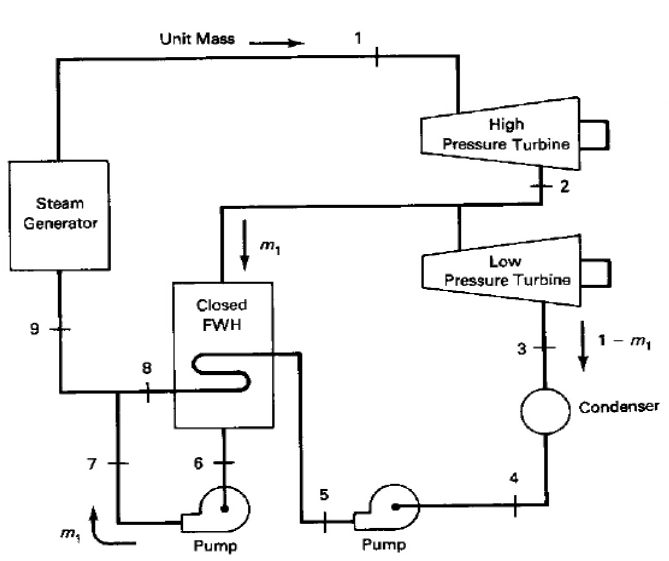

a) Flow Cycle

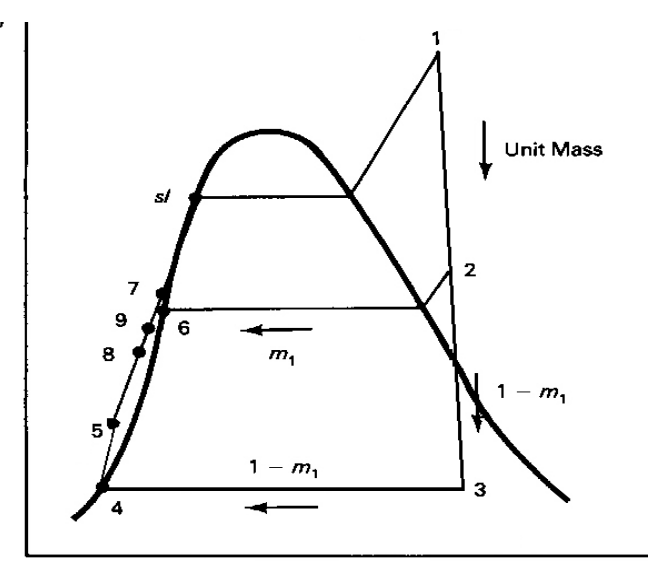

b) T-S diagram

Figure 7. Regenerative Rankine cycle with closed feedwater heater and pumped condensate 


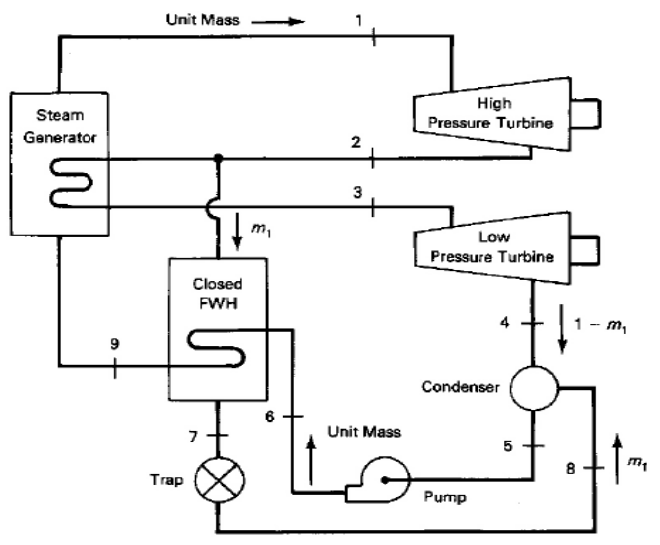

a) Flow Cycle

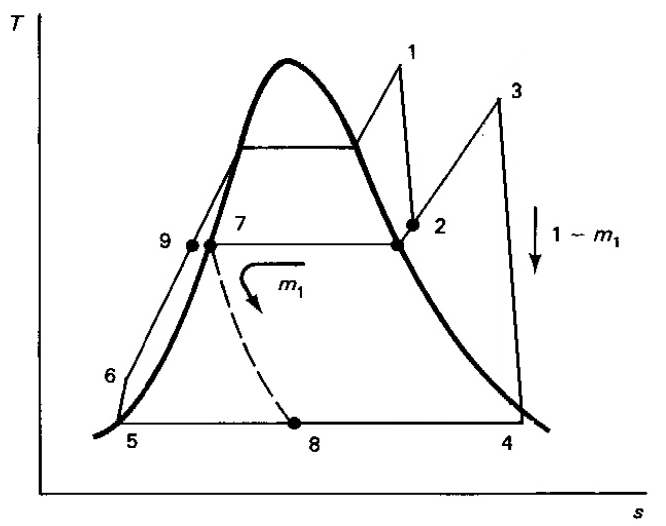

b) T-S diagram

Figure 8. Rankine cycle with reheat and one closed feedwater heater

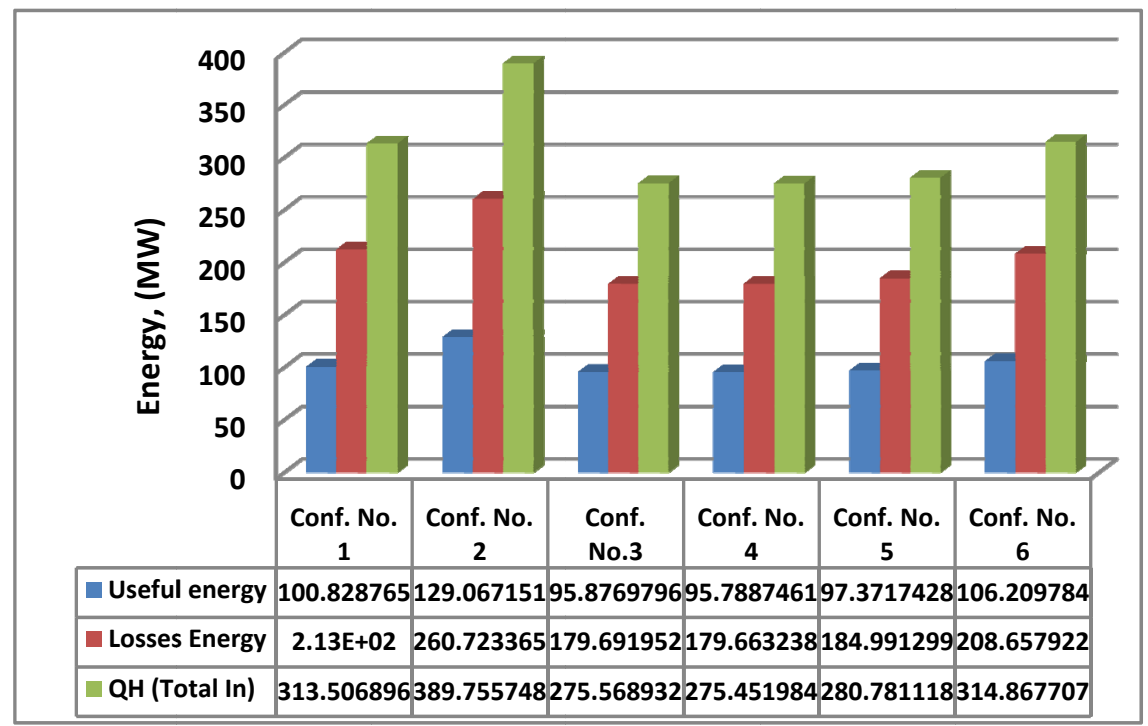

Figure 9. Comparison of input, produced and losess energy for all configurations of cycle

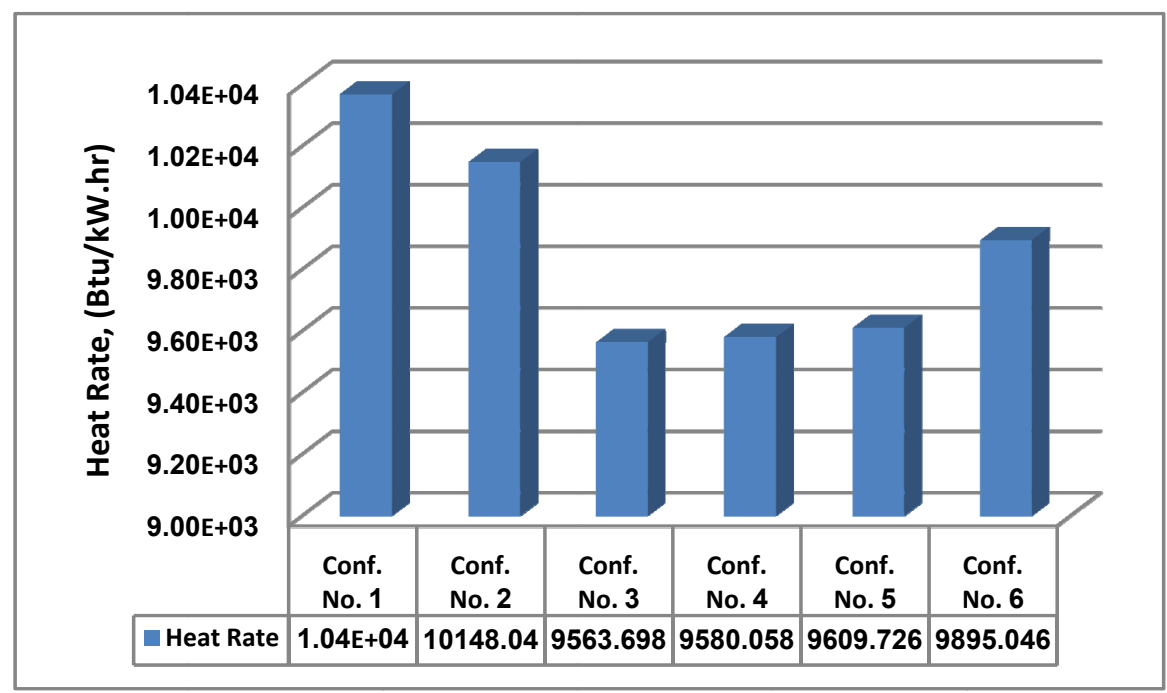

Figure 10. Comparison of Heating rate for all configurations of cycle 


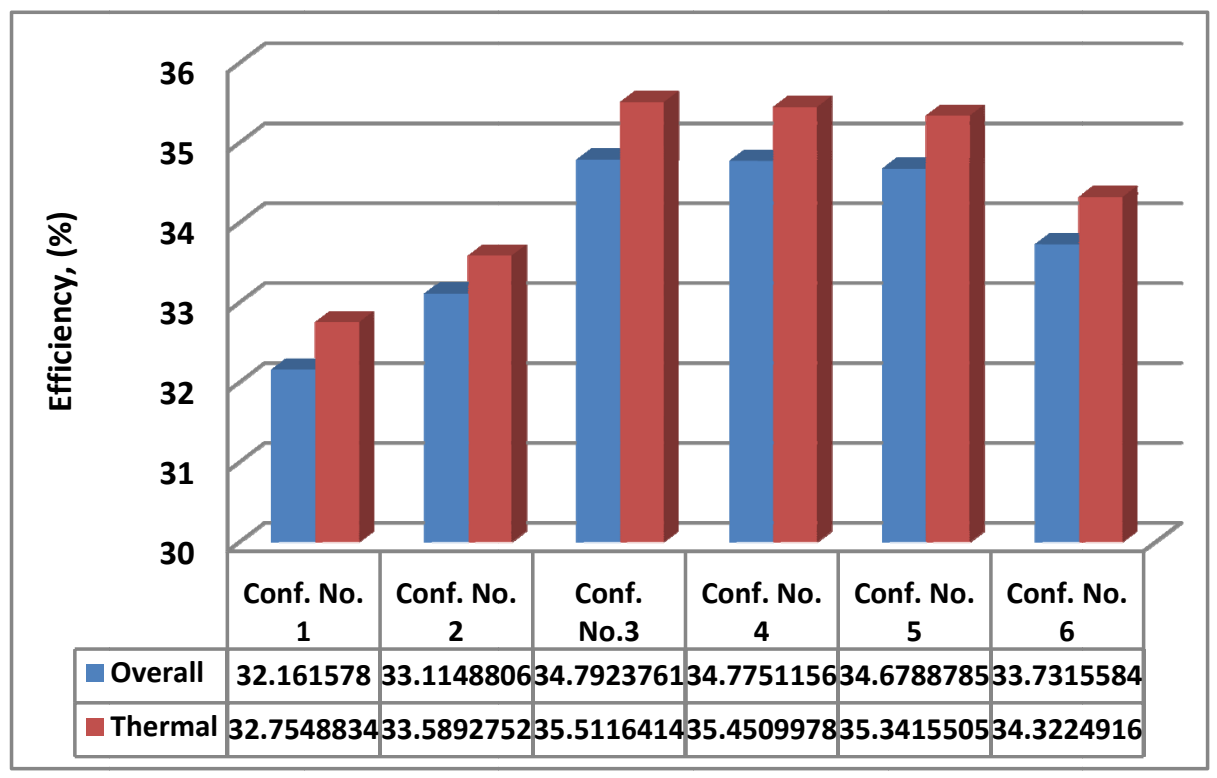

Figure 11. Comparison of Overall and thermal effecinces for all configuartions of cycle

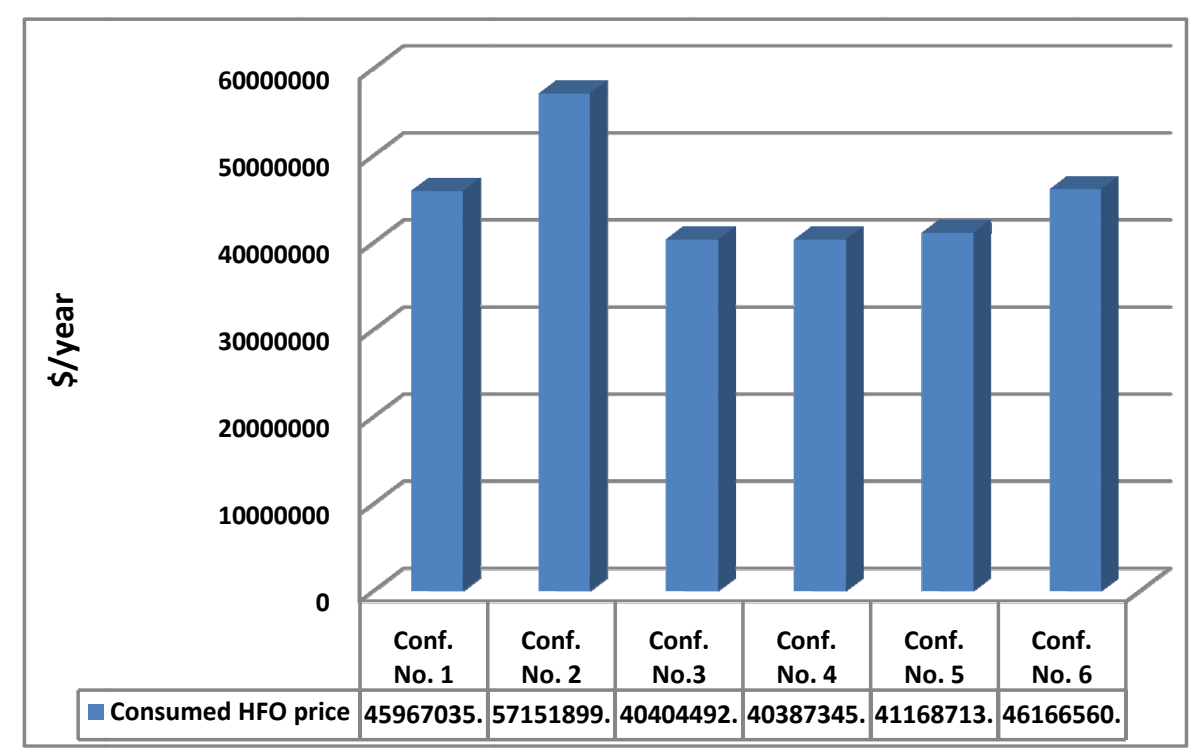

Figure 12. Comparison of consumed prices for all configuartion cycles 